\title{
AVALIAÇÃO DA PREVALÊNCIA DE HPV EM EXAMES PREVENTIVOS REALIZADOS NO PERÍODO DE JANEIRO DE 2014 A DEZEMBRO DE 2016 EM UM LABORATÓRIO PRIVADO NO MUNICÍPIO DE TUBARÃO/SC.
}

DOI: http://dx.doi.org/10.18616/prat10

Gergiane Teixeira Pereira UNESC - Universidade do Extremo Sul Catarinense gergianeteixeirapereira@hotmail.com

Karina Lumertz Hendler UNESC - Universidade do Extremo Sul Catarinense karinalumertzhendler@hotmail.com

Haylla Santos de Sousa UNESC - Universidade do Extremo Sul Catarinense aideehailla@hotmail.com

Emanuel de Souza UNESC - Universidade do Extremo Sul Catarinense emanuel@unesc.net 


\section{INTRODUÇÃO}

A infecção pelo papiloma vírus humano (HPV) é considerada atualmente a doença sexualmente transmissível com maior prevalência em todo o mundo (SILVA et al., 2009). O HPV é membro da família papovaviridae e formam uma família de mais de 130 genótipos que infectam o epitélio de seres humanos persistindo de forma assintomática ou causando neoplasias (SANCLEMENTE; GILL, 2002; BERNARD et al., 2010), podendo permanecer em estado latente por muitos anos, bem como apresentar manifestações clínicas ou subclínicas (FEDRIZZI et al., 2008). Na forma latente o DNA exposto reside no núcleo, a replicação viral fica adjunta ao ciclo celular e as células infectadas têm aparência normal. Na forma subclínica a infecção no colo uterino e nos genitais masculinos é mais frequente; infecção pode estar associada à neoplasia intraepitelial. Em uma manifestação clínica, as lesões são observadas sem maiores dificuldades (IGANSI, 2005).

$\mathrm{O}$ vírus HPV pode ser dividido em tipos cutâneos ou de mucosa. $\mathrm{O}$ HPV de mucosa é dividido nos tipos de riscos "alto", "intermediário" e "baixo" dependendo da lesão com a qual estão associados. Tipos de alto-risco tais como o 16, 18, 31, 33 e 35 são predominantemente associados ao câncer cervical, que é um importante problema de saúde pública que, depois do câncer de mama, é um dos principais responsáveis pelas mortes do sexo feminino. HPVs de baixo risco, tais como os tipos 6 e 11, induzem hiperproliferações benignas do epitélio, como papilomas ou verrugas (RIVOIRE, 2006; ZARDO et al., 2014; MARQUES, 2012). Os condilomas acuminados (papilomas, verrugas) dos órgãos genitais externos em geral são pequenas neoformações sésseis, papilares, únicas ou múltiplas, localizadas ou difusas e de tamanho variável. No homem, em geral, ocorrem lesões na glande, sulco balanoprepucial e região perianal e, na mulher, vulva, períneo, região perianal, vagina e colo (IGANSI, 2005).

A transmissão do HPV é feita através do contato direto com mucosa ou pela genital infectada (JUCKET et al., 2010). A população masculina é a principal responsável pela transmissão da infecção ao sexo feminino, que 
ocorre de forma sexual. Isso se dá, pois, diferente de outras doenças sexualmente transmissíveis (DST), o HPV é transmitido mais facilmente do homem para a mulher do que da mulher para o homem, por razão do epitélio do colo do útero ser menos resistente do que o pênis do homem e durante o ato sexual, podem acontecer lesões no epitélio vaginal, gerando uma vulnerabilidade à infecção por HPV, devido o mesmo necessitar do contato direto com os ferimentos (ZARDO et al., 2014; RODRIGUES; SOUSA, 2015). Pode também ocorrer transmissão não sexual, como ocorre com as verrugas cutâneas, por fômites (toalhas, roupas íntimas etc.) e materno-fetal (gestacional, intra e periparto). Embora não se saiba por quanto tempo o vírus resista fora do organismo, considera-se que a transmissão por fômites seja viável por um curto período de tempo (FEDRIZZI et al., 2008).

Entre os fatores de risco para a infecção pelo HPV, os mais relevantes são: ser mulher jovem sexualmente ativa, grupo este que apresenta as taxas mais altas de prevalência da infecção viral, entre 50 e $80 \%$ após dois a três anos do início da atividade sexual; o número de parceiros sexuais durante a vida e a idade do parceiro masculino em relação à da mulher, quanto maior essa diferença, maior o risco (OLIVEIRA et al., 2013). Durante a gravidez o risco de infecção pelo HPV é mais elevado, devido a associação entre a elevação dos níveis hormonais e a imunossupressão (ANGELI et al., 2007). A ocorrência de infecção durante a gravidez não implica em má formação do feto (INCA, 2017).

A melhor arma contra o câncer causado pelo Papilomavirus Humano é a prevenção, através do uso do preservativo durante a relação sexual, evitando assim o contágio pelo vírus. Outra forma, ainda em desenvolvimento para prevenir a infecção pelo vírus é a vacina (CARDOSO, 2012), existem duas vacinas profiláticas contra HPV aprovadas e registradas pela agência nacional de vigilância sanitária (ANVISA) e que estão comercialmente disponíveis: a vacina quadrivalente, que confere proteção contra HPV 6, 11, 16 e 18; e a vacina bivalente, que confere proteção contra HPV 16 e 18. Nenhuma das vacinas é terapêutica, ou seja, não há eficácia contra infecções ou lesões já existentes (INCA, 2017). 
Segundo o Ministério da Saúde o câncer não é uma doença única e sim um conjunto de mais de 100 doenças diferentes e, é resultante de alterações que determinam um crescimento celular desordenado, não controlado pelo organismo e que compromete tecidos e órgãos. No caso do câncer do colo do útero, o órgão acometido é o útero, em uma parte específica - o colo, que fica em contato com a vagina. Classicamente, a história natural do câncer do colo do útero é descrita como uma afecção inicialmente de caráter benigna, com transformações intraepiteliais progressivas que podem evoluir para uma lesão cancerosa invasora, num prazo de 10 a 20 anos, esse intervalo de tempo relativamente longo, permite que ações preventivas sejam realizadas com o objetivo de romper a cadeia epidemiológica da doença (DAMACENA et al., 2017).

O câncer do colo do útero é um importante problema de saúde pública mundial tendo causa multifatorial e, se não diagnosticada e tratada precocemente, poderá evoluir para o carcinoma invasivo (SILVA et al., 2014). A doença está entre os tipos de cânceres que mais acometem mulheres em idade sexualmente ativa, sendo a terceira maior e a quarta causa de mortalidade em mulheres no Brasil, com incidência anual de 16.340 casos, risco estimado de 15,85 casos por 100 mil mulheres e taxa de mortalidade de 4,86 casos por 100 mulheres (SANTOS; SOUZA, 2013; BARCELOS et al., 2017).

Entre os fatores que estão envolvidos nesse processo neoplásico, o HPV é apontado como principal fator, porém admite-se que outros cofatores estão associados no desenvolvimento neoplásico do carcinoma uterino, como a multiplicidade de parceiros sexuais, histórico de outras doenças sexualmente transmissíveis, tabagismo, início precoce da atividade sexual, desnutrição, a situação socioeconômica, fragilidade das estratégias de saúde, higiene íntima inadequada, uso prolongado de contraceptivos orais, fatores imunológicos e hormonais e a baixa escolaridade (SANTOS; SOUZA, 2013).

O colo uterino é revestido por várias camadas de células epiteliais pavimentosas, arranjadas de forma bastante ordenada. Nas neoplasias intraepiteliais, essa estratificação fica desordenada. Quando a desordenação ocorre nas camadas mais basais do epitélio estratificado, estamos diante de uma dis- 
plasia leve ou neoplasia intraepitelial cervical grau I (NIC I). Cerca de 60\% das mulheres com NIC I vão apresentar regressão espontânea, 30\% podem apresentar persistência da lesão como tal e, das demais, menos de $10 \%$ irão evoluir para NIC III, sendo a progressão para o câncer invasor estimada em cerca de $1 \%$. Se a desordenação avança até os três quartos de espessura do epitélio, preservando as camadas mais superficiais, estamos diante de uma displasia moderada ou NIC II. Na NIC III, o desarranjo é observado em todas as camadas.

Essa desordenação das camadas é acompanhada por alterações nas células que vão desde núcleos mais corados até figuras atípicas de divisão celular. A coilocitose, alteração que sugere a infecção pelo HPV, pode estar presente ou não. Quando as alterações celulares se tornam mais intensas e o grau de desarranjo é tal que as células invadem o tecido conjuntivo do colo do útero abaixo do epitélio, temos o carcinoma invasor. Para chegar a câncer invasor, a lesão não tem, obrigatoriamente, que passar por todas essas etapas. As lesões de alto grau são consideradas como as verdadeiras precursoras do câncer e, se não tratadas, em boa proporção dos casos, evoluirão para o carcinoma invasor do colo do útero (MINISTÉRIO DA SAÚDE, 2002).

O exame de citologia oncótica (Papanicolaou) ainda constitui o principal método utilizado para a detecção do câncer do colo uterino e de suas lesões precursoras. A técnica, descrita por George Papanicolau, em 1941, consiste na avaliação morfológica das células de esfregaços obtidos da superfície do colo uterino (TERMINI; VILLA, 2008). O método do Papanicolau consiste em coletar o material cervical do colo uterino e do seu óstio e é realizado pelo profissional de saúde. Esse método utiliza o material coletado e fixado em lâmina e, posteriormente corado utilizando uma série de corantes que tem como objetivo a evidenciação de variações na morfologia e nos graus de maturidade e atividade metabólica celular, possibilitando a identificação das alterações celulares típicas compatíveis com a presença do HPV (SANTOS; SOUZA, 2013; CAPUTO; MOTA; GITIRANA et al., 2010).

O Papanicolau se baseia no uso de um corante básico (apresenta afinidade pelo núcleo, tal como a hematoxilina), um corante ácido (apresenta 
afinidade com o citoplasma de células queratinizadas, tal como orange g) e um corante policromático (gera tonalidades diferentes no citoplasma celular, tal como o ea-65). Essa metodologia apresenta cinco fases: hidratação, coloração nuclear, desidratação, coloração citoplasmática, desidratação, clarificação e selagem (CAPUTO; MOTA; GITIRANA et al., 2010).

É de suma relevância destacar que o Papanicolaou auxilia na detecção das lesões celulares, antes que as lesões evoluam para o câncer, e não na detecção do HPV. Quando identificadas as lesões, são necessários exames complementares para o correto diagnóstico. Assim, a realização do exame Papanicolaou detecta somente as alterações induzidas por HPV e não o vírus propriamente dito, possuindo baixa sensibilidade. Apenas métodos moleculares são capazes de identificar o vírus, como a captura híbrida e a reação em cadeia da polimerase, mas continua sendo um meio eficaz para controlar e interromper o desenvolvimento neoplásico e a malignidade do câncer. Porém, a eficiência das estratégias e tecnologias utilizadas na prevenção do câncer cervical uterino defrontam-se ainda na falta de informação adequada, o que contribui para o diagnóstico tardio da doença e, consequentemente, no aumento de sua mortalidade (SANTOS; SOUZA 2013; SILVA et al., 2014).

As alterações precárias das células cervicais e os cânceres iniciais do colo do útero geralmente não causam sintomas. Por este motivo, o rastreio regular através de exames de Papanicolau ajuda a capturar as alterações das células pré-cancerosas precocemente e prevenir o desenvolvimento de câncer cervical. Possíveis sintomas de doença mais avançada podem incluir sangramento vaginal anormal ou irregular, dor durante o sexo ou secreção vaginal. O câncer cervical precoce pode ser curado pela remoção ou destruição do tecido pré-canceroso ou cancerígeno. Existem várias formas cirúrgicas para fazer isso sem remover o útero ou danificar o colo do útero, de modo que uma mulher ainda possa ter filhos no futuro. Os tipos de cirurgia para câncer cervical precoce incluem o procedimento de excisão eletrocirúrgica em loop (LEEP) - usa eletricidade para remover tecido anormal, a crioterapia - congela células anormais e a terapia com laser - usa luz para queimar tecido anormal (AMERICAN SEXUAL HEALTH ASSOCIATION, 2017). 
A prevalência da infecção cervicovaginal pelo HPV varia muito ao redor do mundo. Além disso, sofre influência de diversos fatores (GONÇALVES, 2016). Neste contexto, assim como Fedrizzi et al., (2008) relata em sua pesquisa que conhecer a prevalência da infecção pelo HPV em nosso meio, torna-se fundamental, para mapear o verdadeiro cenário em nosso país e principalmente porque estes estudos serão importantes para se avaliar em que regiões é mais urgente o incremento da prevenção da infecção HPV. Este trabalho consiste em estabelecer a prevalência de HPV através de dados de um laboratório privado, com exames oriundos do sistema privado e inclusive do Sistema Único de Saúde (SUS).

\section{MÉTODOS}

O trabalho trata-se de um estudo retrospectivo, descritivo, com consulta ao banco de dados no Laboratório Di Prever, no município de TubarãoSC e tem abordagem quantitativa, sendo utilizados dados de mulheres que realizaram os exames preventivo, atendidas pelo Laboratório Di Prever, no período de janeiro de 2014 a dezembro de 2016.

Foram coletados dados de exames preventivos para HPV, atendidas pelo Laboratório Di Prever, no período de janeiro de 2014 a dezembro de 2016, caracterizando a coleta como censitária. Conforme Rodrigues (2002) uma coleta censitária é caracterizada pela observação de todos os elementos pertencentes a população alvo.

Foram incluídas no estudo pacientes de qualquer faixa etária, que realizaram exame preventivo, positivo ou não. Tiveram seus resultados excluídos os pacientes que realizaram outros tipos de exames que não o preventivo.

O projeto foi encaminhado ao Laboratório Di Prever Tubarão-SC. Logo, foi redigida uma carta de aceitação para que os dados obtidos pudessem ser disponibilizados. Posteriormente, o projeto foi submetido ao Comitê de Ética para Pesquisa com Seres Humanos da Universidade do Extremo Sul Catarinense - UNESC onde foi aprovado e gerado um número de protoco- 
lo (2.563.800), atendendo as exigências das Normas da Pesquisa em Seres Humanos, que integram a resolução n. 196/96 do Conselho Nacional de Saúde (CNS), referente aos aspectos éticos das pesquisas que envolvem seres humanos. Contudo, esta pesquisa foi realizada respeitando a dignidade, confidencialidade, privacidade, anonimato e a proteção das pacientes que realizaram o exame citopatológico no Laboratório Di Prever Tubarão-SC.

Os riscos presumíveis se enfatizam aos valores éticos resguardados pela resolução n. 466/12 da Pesquisa com seres humanos, ao qual, serão garantidos o anonimato e o sigilo referente à consulta pelo banco de dados no Laboratório citopatológico. Através da pesquisa foi possível estimar a prevalência de infecção por HPV, podendo assim, auxiliar na promoção de novas políticas públicas de atenção a população.

A análise estatística foi realizada com auxílio do software IBM Statistical Package for the Social Sciencies (SPSS) versão 20.0. As variáveis coletadas foram expressas por meio de frequências e porcentagens. Os testes estatísticos foram realizados com um nível de significância $\alpha=0,05$ e, portanto, confiança de $95 \%$.

A investigação da existência de associação entre as variáveis HPV positivo, HPV negativo e faixa etária foi realizada por meio da aplicação do teste Qui-quadrado de Pearson seguido de análise de resíduo caso houvesse significância estatística.

Foram analisados os dados no período de janeiro de 2014 a dezembro de 2016.Posteriormente, realizou-se uma consulta no banco de dados através dos computadores do laboratório onde foram pesquisados através de uma lista de todas as pacientes que realizaram o exame preventivo nos anos de 2014, 2015 e 2016.

Ao final, buscou-se pelo nome dessas pacientes para avaliar a presença, ou não de HPV, as pacientes que não tiveram nenhuma alteração no exame foram automaticamente excluídas do trabalho. Dessas pacientes selecionadas foram verificados os tipos de alterações, idade e a quantidade de repetições de exames. 
Os dados foram coletados através do banco de dados do laboratório e convertidos em planilhas do Excel. Os mesmos foram tratados e posteriormente organizados num banco de dados no programa SPSS versão 20.0 para a análise estatística. Por se tratar de uma pesquisa retrospectiva não houve a necessidade da assinatura do Termo de Consentimento Livre e Esclarecido por parte das pacientes.

\section{RESULTADOS}

Os exames citopatológicos coletados entre os anos de 2014 e 2016 em um laboratório privado de Tubarão corresponderam a um total de 53.500 laudos. Desses laudos coletados, verificou-se que a idade média das pacientes foi de 35,31 \pm 13,88 anos, tendo como idade mínima 13 e máxima 82 anos. Em relação ao número de laudos dentro do período analisado (53.500), 96 foram insatisfatórios, 51.921 eram negativos e 1483 apresentaram alguma alteração celular (Atipias, LSIL, HSIL, Carcinoma Invasor ou micro invasor e AIS) (Tabela 1).

Tabela 1 - Exames Colpocitológicos Oncóticos.

\begin{tabular}{c|c}
\hline Variável & $\mathbf{n ~ ( \% ) ~ / ~} \mathbf{n} \mathbf{5 3 . 5 0 0}$ \\
\hline Insatisfatório & 96 \\
\hline Negativo & 51.921 \\
\hline Atipias & 1.103 \\
\hline LSIL & 225 \\
\hline HSIL & 153 \\
\hline Invasor & 2 \\
\hline
\end{tabular}

Fonte: Dados Obtidos pela Pesquisa, 2018. 


\section{PRÁTICAS E SABERES EM

Destes, 122 laudos foram excluídos por se tratar de laudos repetidos, restando assim 1.361 laudos significativos e importantes para pesquisa perante os objetivos do trabalho (Tabela 2).

Tabela 2 - Alterações Celulares.

\begin{tabular}{c|c}
\hline Variável & $\mathbf{n ~ ( \% ) ~ / ~} \mathbf{n} \mathbf{1 3 6 1}$ \\
\hline Atipias & 1.035 \\
\hline LSIL & 199 \\
\hline HSIL & 123 \\
\hline Invasor & 1 \\
\hline Microinvasor & 1 \\
\hline AIS & 1 \\
\hline
\end{tabular}

Fonte: Dados Obtidos pela Pesquisa, 2018.

Sendo assim apenas 349 (26,0\%) exames apresentaram alteração compatíveis com HPV conforme mostra a Tabela 3. As alterações que tiveram compatibilidade com HPV foram Lesão escamosa intraepitelial de baixo grau (LSIL); Lesão escamosa intraepitelial de alto grau (HSIL); Carcinoma Invasivo; Carcinoma Micro Invasivo; Adenocarcinoma in situ (AIS).

Tabela 3 - HPV.

\begin{tabular}{c|c}
\hline Variável - HPV & $\mathbf{n}(\mathbf{\%}) / \mathbf{n}=\mathbf{1 3 6 1}$ \\
\hline Sim & $349(26,0)$ \\
\hline Não & $1012(74,0)$ \\
\hline
\end{tabular}

Fonte: Dados Obtidos pela Pesquisa, 2018.

Como descrito na Tabela 4 abaixo, a faixa etária mais prevalente no estudo foi entre 24 e 34 anos (29,8\%), já a idade que apareceu com uma maior frequência de exames positivos analisadas individualmente foi de 20 anos de idade $(6,4 \%)$. 
Tabela 4 - Frequência Faixa Etária

\begin{tabular}{l|c|c}
\hline \multicolumn{2}{|c|}{ Variáveis } & $\mathbf{n}(\%) / \mathbf{n}=\mathbf{1 3 6 1}$ \\
\hline Faixa Etária & Frequência & Porcentagem \\
\hline $\mathbf{1 3}-\mathbf{2 3}$ anos & 332 & 24,4 \\
\hline $\mathbf{2 4}-\mathbf{3 4}$ anos & 406 & 29,8 \\
\hline $\mathbf{3 5}-\mathbf{4 5}$ anos & 301 & 22,1 \\
\hline $\mathbf{4 6}-\mathbf{5 6}$ anos & 212 & 15,6 \\
\hline $\mathbf{5 7}-\mathbf{6 7}$ anos & 78 & 5,7 \\
\hline $\mathbf{6 8}-\mathbf{8 2}$ anos & 32 & 2,4 \\
\hline
\end{tabular}

Fonte: Dados Obtidos pela Pesquisa, 2018.

A Tabela 5, mostra que, a média de realização de exames é de 1,09 por paciente e, através da Tabela 6 , pode-se observar o número de exames repetidos por paciente com alteração celular, 1.257 (92,2\%) pacientes repetiram o exame somente uma vez ao longo do período estudado, 95 (7,0\%) pacientes repetiram o exame duas vezes, $9(0,7 \%)$ repetiram o exame três vezes e $1(0,1 \%)$ repetiu o exame quatro vezes e $1(0,1 \%)$ repetiu o exame por cinco vezes.

Tabela 5 - Média de Exame por Paciente.

\begin{tabular}{c|c|c|c|c}
\hline $\mathbf{N}$ & Mínimo & Máximo & Média & Desvio padrão \\
\hline 1.363 & 1 & 5 & 1,09 & 0,327 \\
\hline
\end{tabular}

Fonte: Dados Obtidos pela Pesquisa, 2018.

Tabela 6 - Quantidade de Exames.

\begin{tabular}{c|c|c}
\hline Variáveis & Frequência & $\mathbf{n}(\%)$ \\
\hline Apenas uma vez & 1.257 & 92,2 \\
\hline Duas vezes & 95 & 7,0 \\
\hline Três vezes & 9 & 0,7 \\
\hline Quatro vezes & 1 & 0,1 \\
\hline Cinco vezes & 1 & 0,1 \\
\hline
\end{tabular}

Fonte: Dados Obtidos pela Pesquisa, 2018. 
Os últimos dados estimados pela Organização Mundial de Saúde (OMS) demonstraram que aproximadamente 440 milhões de pessoas têm infecção por HPV genital em todo o mundo. Além disso, estima-se que $80 \%$ das mulheres venham a adquirir pelo menos uma infecção por um dos tipos de HPV durante sua vida (CÂNDIDO et al., 2017).

A prevalência de HPV no estudo mostrou-se consideravelmente baixa (26\%) em relação ao que se esperava e quando comparada a outros estudos que apresentaram resultados mais significativos para HPV, como uma pesquisa que foi recentemente realizada pelo Hospital Moinhos de Vento em parceria com o MS para avaliar a prevalência de HPV no Brasil com resultados de 54,6\% e 44\% na região de Florianópolis, SC (POP-Brasil, 2017).

No estudo de Fredrizzi et al. foram avaliadas 100 amostras de material cérvico-vaginal, onde foram encontrados DNA-HPV em 21 participantes (21\%) - enquanto Carvalho et al. obteve como resultado 510 (48,3\%) amostras de mulheres que apresentaram infecção pelo HPV.

A ampla variação nas estimativas é explicada pelas diferenças nas médias de idade das populações estudadas e a sensibilidade do método utilizado para detecção da infecção pelo HPV. (Fedrizzi et al., 2008)

A prevalência de HPV varia muito em todo mundo e sofre influência de vários fatores como afirma Fedrizzi et al. (2008). A baixa prevalência obtida neste estudo pode ser explicada pelo fato de a região estudada ter uma população pequena em comparação com as grandes cidades fazendo com que tenham fácil acesso aos exames preventivos, e outras medidas de prevenção.

Estima-se que a maior parte das mulheres é infectada pelo HPV genital no início da atividade sexual, e sua incidência torna-se evidente na fase juvenil da população feminina entre 20 e 29 anos de idade e diminui com avanço da maturidade, e o segundo pico da doença encontra-se entre 50 e 60 anos (MACHADO; PIRES, 2017).

A faixa etária mais prevalente foi entre 24 e 34 anos e a idade com uma maior frequência foi de 20 anos, confirmando assim outros estudos, segundo Carvalho et.al. A média de idade das participantes da pesquisa foi 31,5 
anos e a faixa etária mais prevalente foi entre 21 e 30 anos de idade. E isso pode se justificar pela ocorrência dos jovens estarem mais vulneráveis ao vírus por ser sexualmente mais ativos e possivelmente por possuir múltiplos parceiros. Fedrizzi et al. afirmam que dos casos positivos, $48 \%$ ocorreram na faixa etária até os 30 anos, sendo a maior parte em mulheres entre 21 anos e 25 anos (24\%), as mulheres com idade entre 21 anos e 25 anos corresponderam à faixa etária em que se observou a maior prevalência da infecção pelo HPV (38\%), seguida pela faixa etária de 36 a 40 anos (36\%).

Podemos observar que entre as idades 45 aos 56 anos teve uma quantidade significativa de exames positivos e, segundo Girianeli, Thuler e Silva (2010), isso se explica pelas mudanças hormonais relacionadas à menopausa que poderiam deixar a mulher mais vulnerável à infecção ou à reativação de infecção latente ou também pode ser justificado pelo aumento da expectativa de vida, que ocorre devido à queda nos coeficientes de fecundidade e de mortalidade.

O Ministério da Saúde faz recomendação de que mulheres na faixa etária de 25 a 65 façam o exame anualmente. Após dois exames negativos, com intervalo de um ano cada, o rastreamento só será feito novamente em três anos (INCA, 2014). Porém, se o resultado aponta um resultado sugestivo de infecção por HPV ou lesão de baixo grau, a orientação dada a paciente é de que ela repita o exame de Papanicolau em seis meses e se o resultado persistir como o anterior, a conduta será dada pelo médico e a realização da colposcopia já será indicada. Em alguns casos podem ocorrer de ter um resultado apresentando uma amostra insatisfatória, então essa paciente deverá ser convidada a repetir o exame entre seis e dose semanas (INCA, 2011).

No estudo teve maior porcentagem de exames repetidos apenas uma vez, por mulheres que apresentaram alguma alteração na célula, sendo que essa mesma mulher deveria repetir o exame em pelo menos seis meses, ou procurar ajuda médica para averiguar melhor essa alteração celular. Segundo Da Silva et. al., quanto a frequência da realização do exame, uma grande parte $(43,6 \%)$ relatou que ele deve ser repetido a cada ano, e outra parte $(43,6 \%)$ que deve ser repetido a cada dois anos independente se tiver alteração ou não. 


\section{CONCLUSÃO}

O desenvolvimento do presente estudo demonstrou uma baixa prevalência de HPV (Papilomavirus), apontando que a realização do exame citopatológico é de grande importância na saúde da mulher.

A idade mais prevalente em exames positivos foi de 20 anos e a média do número de exames realizados por paciente com alteração é de 1,9 sendo o número mínimo de exames por paciente com alteração celular de 1 e o máximo de exames 5. Contudo pode se ver o quão importante é a precaução, como uso de preservativos e, principalmente, a realização de exames preventivos pelo menos uma vez ao ano.

Além da triagem para avaliar infecção por HPV, outras patologias podem ser diagnosticadas através do exame preventivo, sendo assim, o presente estudo abre a possibilidade para que outros trabalhos sejam desenvolvidos nessa área a fim de que mais medidas de promoção a saúde sejam desenvolvidas e que os índices futuros sejam ainda melhores.

\section{REFERÊNCIAS}

ANGELI, S. Detecção de DNA de Papilomavirus Humano (HPV) em mulheres grávidas utilizando a urina. Revista de Iniciação cientifica da Ulbra. 2017. Disponível em: http://www.periodicos.ulbra.br/index.php/ic/article/ view/1696/1235. Acesso em: 25 set. 2017.

\section{AMERICAN SEXUAL HEALTH AMERICAN. National Cervical Cancer}

Coalition. 2017. Disponível em: <http://www.nccc-online.org>. Acesso em: 18 out. 2017.

BARCELOS, M. R. et al. Qualidade Do Rastreamento Do Câncer de Colo Uterino No Brasil: Avaliação Externa Do PMAQ. Revista Saúde Pública, São Paulo. 2017; v. 51, n. 67. Disponível em: <http://www.scielo.br/scielo.php >. Acesso em: 14 out. 2017. 
BERNARD, H. U.; BURK, R. D.; CHEN, Z.; VAN DOORSLAER, K.; ZUR HAUSEN, H., DE VILIERS, E. M. Classification of papillomaviruses (PVs) based on 189 PV types and proposal of taxonomic amendments. Virology. 2010. Disponível em: <https://www.ncbi.nlm.nih.gov/pubmed/20206957>. Acesso em: 25 set. 2017.

CÂNDIDO, S.; DUARTE, E.; SANTOS, E.; LIMA, G.; COSTA, M.; SOUZA, P.; DINIZ, M. Infecção por Papilomavírus Humano de alto risco Oncogênico em mulheres. Medicina Veterinária (UFRPE), Recife. 2017; v. 11, n. 4, p. 270-278. Disponível: <http://www.journals.ufrpe.br/index.php/medicinaveterinaria/ article/view/1956/482482577>. Acesso em: maio 2018.

CAPUTO, L.; MOTA, E.; GITIRANA, L. Conceitos e métodos para a formação de profissionais em laboratórios de saúde. Fiocruz. 2010; v. 4. Disponível em: $<$ http://www.epsjv.fiocruz.br/sites/default/files/capitulo_4_vol2.pdf $>$. Acesso em: 11 maio 2018.

CARDOSO, E. Aspectos históricos, Fisiopatológicos e preventivos da infecção por papiloma vírus humano-HPV. Universidade Federal de Minas Gerais. Curso de especialização em atenção básica em saúde da família. Minas Gerais. 2012, p. 10.

CARVALHO, M. O. O. et al. Detection of human papillomavirus DNA by the hybrid capture assay. Braz J Infect Dis [online]. 2003, v. 7, n. 2, pp. 121-125. ISSN 1413-8670. http://dx.doi.org/10.1590/S1413-86702003000200004.

DAMACENA, A. M.; LUZ, L. L.; MATTOS, I. E. Rastreamento do câncer do colo do útero em Teresina, Piauí: estudo avaliativo dos dados do sistema de informação do Câncer do Colo Útero, 2006-2013. Epidemiologia e Serviço de Saúde, v. 26, n. 1, p. 17. 2017.

SILVA, L. S. R. da; LESSA, E. C.; SILVA, T. M. da et al. Adesão ao exame papanicolau por mulheres jovens em Unidade Básica de Saúde. Rev enferm UFPE [on line]., Recife, 10(12):4637-45, dez., 2016. Disponível em: <http:// pesquisa.bvsalud.org/cvsp/resource/pt/bde-30194?lang=pt $>$. Acesso em: 6 jun. 2018. 
FEDRIZZI, E. M; SCHLUP, C. G.; MENEZES, M. E.; CAMPOS, O. M. Infecção pelo Papilomavirus humano (HPV) em mulheres de Florianópolis, Santa Catarina [Human Papillomavirus (HPV) infecction in women of Florianopolis, Santa Catarina, Brazil]. DST K Bras Doenças Sexualmente Transmissíveis, 2008. Disponível em: <http://www.dst.uff.br//revista20-2-2008/1.pdf>. Acesso em: 25 set. 2017.

GIRIANELLI, V. R.; THULER, L. C. S.; SILVA, G. A. Prevalência de HPV em mulheres assistidas pela estratégia saúde da família na Baixada Fluminense do Estado do Rio de Janeiro. Revista Brasileira de Ginecologia Obstetrícia. 2010; v. 32, n. 1, p.39-46. Disponível em: <http://dx.doi.org/10.1590/S0100$72032010000100007>$. Acesso em: 25 set. 2017.

GONÇALVES, L. F. Prevalência e genotipagem do papilomavírus humano (HPV) na região cervicovaginal das mulheres atendidas em clínica privada de ginecologia no município de Joaçaba. Universidade do Oeste de Santa Catarina centro de ciências da vida mestrado em biociências e saúde. Joaçaba. 2016, p. 15.

INCA - INSTITUTO NACIONAL DE CÂNCER. Estimativa 2014: incidência de câncer no Brasil/Instituto Nacional de Câncer, Rio de Janeiro, 2014.

INCA - INSTITUTO NACIONAL DE CÂNCER. Rio de Janeiro, 1996-2017. Disponível em: <http://www.inca.gov.br> Acesso em: 25 set. 2017.

IGANSI, C. N. Prevalência de papilomavírus humano (HPV) e chlamydia trachomatis (CT) e sua associação com lesões cervicais em uma amostra de mulheres assintomáticas de Porto Alegre, 2005. Disponível em: <http://hdl. handle.net/10183/7194>. Acesso em: 25 set. 2017.

JUCKETT, G; HARTMAN-ADAMS, H. Human Papilomavirus: Clinical Manifestations and Prevention. America Family Physician. 2010. [Acesso em 25 Set 2017]. Disponível em:https://www.researchgate.net/ publication/49648847_Human_Papillomavirus_clinical_Manifestations_ and_Prevention. 
MACHADO L. S.; PIRES, M. C. Perfil epidemiológico de mulheres com papilomavírus humano que utilizam o serviço público de saúde. Rev Baiana Enferm. 2017. Disponível em: <https://portalseer.ufba.br/index.php/ enfermagem/article/view/22135>. Acesso em: 20 maio 2018.

MARQUES, A. E. M. Avaliação da presença do papilomavirus humano em orofaringe de pacientes com neoplasia intraepitelial escamosa de alto grau e carcinoma invasivo do colo do útero, e de seus companheiros no Hospital Universitário de Brasília, Brasília, DF. 2012. 115 f., il. Dissertação (Mestrado em ciências da saúde) - Universidade de Brasília, Brasília, 2012. Disponível em: http://repositorio.unb.br/handle/10482/12358. Acesso em: 25 set. 2017.

MASCHIO, M. B. M.; BALBINO, A. P.; DE SOUZA, P. F. R.; KALINKE, L. P. Sexualidade na terceira idade: medidas de prevenção para doenças sexualmente transmissíveis e AIDS. Revista Gaúcha de Enfermagem. Porto Alegre (RS). 2011, v. 32, n. 3, p. 583-589. Disponível em: <http://www.scielo. $\mathrm{br} /$ scielo.php? script $=$ sci_arttext $\&$ pid $=$ S1983-14472011000300021 $>$. Acesso em: 30 maio 2018.

POP - Brasil. Estudo Epidemiológico sobre a Prevalência Nacional de Infecção pelo HPV (POP-Brasil): Resultados preliminares - Associação Hospitalar Moinhos de Vento - Porto Alegre, 2017; 120 p.

RIVOIRE, W. A.; CORLETA, H. V. E.; BRUM, I. S.; CAPP, E. Biologia molecular do câncer cervical. Revista Brasileira de Saúde Materno Infantil. 2006; v. 6, n. 4, p. 447-451. Disponível em: http://dx.doi.org/10.1590/S151938292006000400012 . Acesso em: 25 set 2017.

RODRIGUES, A. F.; SOUSA, J. A. Papilomavirus humano: prevenção e diagnóstico. Revista de Epidemiologia e Controle de Infecção. Santa Cruz do Sul. 2015; v. 5, n. 4, p. 197-202. Disponível em: https://online.unisc.br/seer/ index.php/epidemiologia/article/view/6043/4633. Acesso em: 25 set. 2017.

SANCLEMENTE, G.; GILL, D. Biologia molecular e patogênese do papilomavirus humano. Jornal da Academia Europeia de Dermatologia e 
Venereologia. 2002. Disponível em: <https://onlinelibrary.wiley.com/doi/ abs>. Acesso em: 25 set. 2017.

SANTOS, U. M.; SOUZA, S. E. B. Papanicolaou: Diagnóstico Precoce ou Prevenção do Câncer Cervical Uterino? Revista Baiana de Saúde Pública. 2014; (S. L), v. 37, n. 4, p. 971. Disponível em: <http://rbsp.sesab.ba.gov.br/ index.php/rbso/article/view/420>. Acesso em: 14 out. 2017.

SILVA, M.; GONÇALVES, A. K.; GIRALDO, P. C.; Ponte A. C.; DANTAS, G.; SILVA, R. J.; DA SILVA, L. G. A eficácia da vacina profilática contra o HPV nas lesões HPV induzidas. Feminina, Rio de Janeiro. 2009; v.37, n 10, p. 519 - 526. Disponível em: <https:/www.arca.fiocruz.br/handle/icict/10286>. Acesso em: 24 set. 2017.

SILVA, D.; SILVA, A. M.; BRITO, L. M.; GOMES, S.; NASCIMENTO, M.; CHEIN, M. Rastreamento do câncer do colo do útero no Estado do Maranhão, Brasil. Ciência e saúde coletiva. 2014; v.19, n. 4, p. 1163-1170. Disponível em: $<$ http://dx.doi.org/10.1590/1413-81232014194.00372013>. Acesso em: 14 out. 2017.

TERMINI, L.; VILLA, L. L. Biomarcadores na Triagem do Câncer do Colo Uterino. Jornal Brasileiro de Doenças Sexualmente Transmissíveis. 2008. Disponível em: <http://annalab.com.br/uploads/file/8.pdf>. Acesso em: 14 out. 2017.

ZARDO, G.; FARAH, F.; MENDES, F.; FRANCO, C.; MOLINA, G.; MELO, G.; KUSMA, S. Vacina como agente de imunização contra o HPV. Ciência e Saúde Coletiva, Rio de Janeiro. 2014; v. 19, n. 9, p. 3799-3808. Disponível em: <http:// dx.doi.org/10.1590/1413-81232014199.01532013>. Acesso em: 25 set. 2017. 